\title{
The role of GNLY gene polymorphisms in psoriasis pathogenesis*
}

\author{
Esra Ermis ${ }^{1}$, Sevim Karakas Celik ${ }^{1}$, Nilgun Solak², Gunes Cakmak Genc ${ }^{3}$, Ahmet Dursun ${ }^{3}$
}

DOI: http:/ / dx.doi.org/10.1590/abd1806-4841.20198188

\begin{abstract}
BACKGROUND: Psoriasis is a systemic inflammatory disorder that involves complex pathogenic interactions between the innate and adaptive immune systems. The most accepted mechanism in the etiopathogenesis of psoriasis is the induction of inflammation with keratinocyte hyperproliferation. Granulysin (GNLY) is a cytolytic antimicrobial peptide (AMP) that is secreted together with granzyme and perforin from the granules of human cytotoxic T lymphocytes (CTLs) and natural killer (NK) cells. It has been immunohistochemically proven that the expression of granulysin is increased in lesions of psoriasis. OвJестіV: This study aimed to investigate the relationship between psoriasis disease and granulysin gene polymorphisms. Methods: GNLY rs7908 and rs10180391 polymorphisms were studied by PCR-RFLP in 100 psoriasis patients under treatment in the Dermatology Polyclinic of Bulent Ecevit University. In addition, 100 healthy individuals with similar age and sex distribution were used as a control group.

RESULTS: In the control group, GNLY rs7908 CC genotype was significantly higher than in psoriasis patients $(\mathrm{P}=0.031$; OR= 0.305; $\mathrm{Cl}=0.305$ (0.121 - 0.773). In our study, the genotype distributions in patients and control groups were GNLY rs7908 (SNP) GG $(51 \%, 37 \%)$, GC $(41 \%, 44 \%)$, CC (8\%, 19\%); GNLY rs10180391 (SNP) from the CC (41\%, 44\%), CT (42\%, \% 41), TT (17\%, 15\%). STUDY LIMITATIONS: The study only included Turkish patients.

CONCLUSION: Our findings showed that GNLY rs7908 CC genotype and C allele had a protective effect against psoriasis and decreased the disease severity (according to PASI score), whereas rs10180391 SNP did not show any effective role in psoriasis pathogenesis.
\end{abstract}

Keywords: Granulysin; Genetics; Molecular biology; Polymorphism, single nucleotide; Psoriasis

\section{INTRODUCTION}

Psoriasis is a chronic immune-mediated inflammatory skin disease that is not explained simply by Mendelian inheritance. Genetic factors play a role in psoriasis development, although the exact causal mechanism of psoriasis is still unknown. ${ }^{1}$

Psoriasis is seen in nearly $1-3 \%$ of the human population all over the world and at every age. Its adverse effect on health is seriously aggravated by physical disruption of daily activities, shame, anxiety, guilt, social withdrawal, social exclusion, depres- sion, and even suicidal tendencies. Psoriasis patients can also experience heart disease, diabetes mellitus, cancer, and depression. A chronic course involving unexplained remissions and exacerbations requires patients to undergo a treatment and follow-up process that extends throughout their lives. ${ }^{2-4}$

Psoriasis usually appears in the form of well-demarcated, scaly plaques and has been classified in the group of immune-mediated inflammatory diseases, alongside ulcerative colitis, Crohn's

Received 14 February 2018.

Accepted 01 August 2018.

* Work conducted at the Bulent Ecevit University, Zonguldak, Turkey.

Financial Support: The research was supported by the Unit of Scientific Research Projects of Bulent Ecevit University (BAP-2015-50737594-04), Turkey.

Conflict of Interests: None.

Department of Molecular Biology and Genetics, Faculty of Sciences and Arts, Bulent Ecevit University, Zonguldak, Turkey.

Department of Dermatology, Faculty of Medicine, Bulent Ecevit University, Zonguldak, Turkey.

Department of Medical Genetics, Faculty of Medicine, Bulent Ecevit University, Zonguldak, Turkey.

MAILING AdDRESS:

Esra Ermis

E-mail: esraermiss@gmail.com 
disease, rheumatoid arthritis, ankylosing spondylitis, and Behçet's disease. ${ }^{5,6}$ It is known that antimicrobial peptides (AMPs), which provide high resistance to skin infection, show increased synthesis in psoriatic lesions. ${ }^{7}$ AMP production in the skin is the primary mechanism that protects skin against infections, and AMP levels are increased as a result of microbial infections. ${ }^{8}$ Granulysin is a member of the AMP family of cytolytic and proinflammatory peptides. The peptide exists in granules of T cells and natural killer (NK) cells and is secreted from these cells together with granzyme and perforin. ${ }^{9}$ Based on amino acid sequence homology, the 9-kDa granulysin protein belongs to the saposin-like protein (SAPLIP) family, which consists of activators of sphingolipid hydrolase in the central nervous system. Granulysin is tumoricidal and broadly antimicrobial, killing gram-positive and gram-negative bacteria, yeast, fungi, and parasites. Granulysin binds to the cell surface based on charge and appears to make a way through the cell membrane, causing ion fluxes. ${ }^{10}$ A recent immunohistochemistry study showed that granulysin expression is increased in psoriasis lesions. ${ }^{7}$

Granulysin encoding by the GNLY gene is located on 2 p11.2, and several polymorphisms have been identified in GNLY that contain 5 exons. C to T substitution in GNLY (rs10180391 (C/T) is located on 2: 85.699.222, and C to G substitution on GNLY (rs 7908 $(\mathrm{C} / \mathrm{G})$ is located on 2:85.698.633. ${ }^{11}$ It has also been shown that GNLY gene polymorphism is associated with infectious diseases such as chronic hepatitis B, but to our knowledge there has been no study on the relationship between GNLY gene polymorphisms and psoriasis. ${ }^{12}$

Our study investigated the role of GNLY gene polymorphisms in the etiopathogenesis of psoriasis and can help establish a psoriasis susceptibility profile.

\section{METHODS}

\section{Study subjects}

The study was conducted in 100 patients diagnosed with psoriasis in the Polyclinic for Skin and Venereal Diseases of Bulent Ecevit University Application and Research Center. A group of 100 individuals with no autoimmune or autoinflammatory disorders was used as the control group. Study participants were matched for gender and age distribution. The age and gender of all the subjects included in the study were recorded, and patients were divided into groups according to the Psoriasis Area and Severity Index (PASI) score. The study was approved by the Clinical Research Ethics Committee, Bulent Ecevit University (Date 28.05.2015 approval number 2015-24-26/05) and performed in accordance with the ethical standards established in the 1964 Declaration of Helsinki and later amendments. All participants were informed and signed consent forms before being included.

\section{DNA extraction and genotype analyses}

In order to study the GNLY rs7908 and rs10180391 gene polymorphisms, $2 \mathrm{ml}$ blood samples were collected from patients and healthy controls during routine follow-up.

Genomic DNA was extracted from $250 \mu \mathrm{L}$ of peripheral blood with the E.Z.N.A. ${ }^{\circledR}$ Blood DNA Mini Kit (Omega Bio-tek Inc., Atlanta GA), according to the manufacturer's protocol. Polymerase chain reaction (PCR) restriction fragment length polymorphism
(RFLP)-based analysis was used to genotype GNLY rs7908 (C/G) and GNLY rs10180391(C/T) polymorphisms using PCR primers (Tables 1 and 2).

PCR was performed in $25 \mu \mathrm{L}$ containing 20 to $100 \mathrm{ng}$ genomic DNA, $1.5 \mathrm{mM} \mathrm{MgCl}$, 1 x PCR buffer with $\left(\mathrm{NH}_{4}\right)_{2} \mathrm{SO}_{4}, 0.25 \mathrm{mM}$ deoxynucleotide triphosphates (dNTPs), $10 \%$ dimethylsulphoxide, 0.5 units of Taq polymerase, and $20 \mathrm{pmol}$ of each primer.

Amplification conditions for the GNLY rs7908(C/G) polymorphism were initial denaturation at $95^{\circ} \mathrm{C}$ for 3 minutes, then 35 amplification cycles of $60 \mathrm{~s}$ at $95^{\circ} \mathrm{C}, 90 \mathrm{~s}$ at $56^{\circ} \mathrm{C}$, and $60 \mathrm{~s}$ at $72^{\circ} \mathrm{C}$, and a final 7 -minute extension step at $72^{\circ} \mathrm{C}$. The PCR products were checked on $1.5 \%$ agarose gel for assay completion, and then the PCR products with 225 base pairs (bp) were digested overnight with BbvCI restriction enzyme (New England Biolabs) (Figure 1).

Amplification conditions for the GNLY rs10180391(C/T) polymorphism were initial denaturation at $95^{\circ} \mathrm{C}$ for 3 minutes, then 35 amplification cycles of $95^{\circ} \mathrm{C}$ for $60 \mathrm{~s}, 55^{\circ} \mathrm{C}$ for $90 \mathrm{~s}$, and $72^{\circ} \mathrm{C}$ for $60 \mathrm{~s}$, and a final 7 -minute extension step at $72^{\circ} \mathrm{C}$. The PCR products were checked on $1.5 \%$ agarose gel for assay completion, and then the PCR products with 209 base pairs (bp) were digested overnight with AseI restriction enzyme (Thermo Scientific) (Figure 2).

All digestion products were electrophoresed on $3 \%$ agarose gel and viewed by staining with ethidium bromide and evaluated using a gel documentation system (Vilber Lourmat Bio-Print ST4).

\section{Statistical analyses}

A case-control study was performed, and allelic frequencies of the polymorphisms were calculated both for cases and controls. The $\chi^{2}$ test was used to compare the genotype frequency of each gene polymorphism in psoriasis patients and controls. Odds ratios (OR) and $95 \%$ confidence intervals $(\mathrm{CI})$ were calculated to compare the psoriasis risk for the alleles. Distribution of data was determined by the Shapiro-Wilks test. Continuous variables are expressed as mean and standard deviation (SD) or median, and categorical variables as frequency and percent. Continuous variables were compared with the independent-sample t-test or the Mann-Whitney U-test. P values $<0.05$ were considered statistically significant. SPSS version 18.0 was used (SPSS Inc., Chicago, IL).

\section{RESULTS}

The study enrolled 100 psoriasis patients and 100 healthy controls. There was no statistically significant difference in age distribution between patients and controls $(p=0.315)$. Mean age (SD)

\begin{tabular}{|c|c|c|}
\hline SNP ID & Primer sequencing & Annealing temp. $\left({ }^{\circ} \mathrm{C}\right)$ \\
\hline rs7908 & $\begin{array}{l}\text { F: 5'- TGT TCA GTA } \\
\text { GGG TCA GGT GG-3'} \\
\text { R: } 5^{\prime} \text {-GAT TCT GGA } \\
\text { TCG AGG AAG CG -3' }\end{array}$ & $56^{\circ} \mathrm{C}$ \\
\hline rs10180391 & $\begin{array}{l}\text { F: 5'- AAG CAA CAG } \\
\text { AAG TCT CAG CC-3' } \\
\text { R: } 5^{\prime}-\text { CTG CCA AGA } \\
\text { GAG AAG CGA AC -3' }\end{array}$ & $55^{\circ} \mathrm{C}$ \\
\hline
\end{tabular}


was 41.31 years (13.46) in patients and 39.49 years (12.06) in controls (Table 3).

As seen in table 4, the study showed a significant association between the GNLY rs7908 (C/G) polymorphism and psoriasis versus normal controls $(\mathrm{OR}=0.30595 \% \mathrm{CI}=0.121-0.773$; $\mathrm{p}=0.033)$.
The GNLY rs7908 CC genotype was significantly more frequent when compared to the control group (GG genotype) $(p=0.033$, $\mathrm{OR}=0.305 \mathrm{CI}=0.121-0.773)$. Distributions of genotypes of the GNLY rs10180391 (C/T) polymorphism were similar in psoriasis patients and controls, and no relationship was detected between these

TABLE 2: SNP ID, restriction enzymes for detecting each single-nucleotide polymorphism (SNP), cutting sequencing, working temperature, incubation time and allele size (bp)

\begin{tabular}{|c|c|c|c|c|c|}
\hline SNP ID & Restriction enzymes & Cutting sequencing & Working temperature & Incubation time & Allele size (bp) \\
\hline \multirow{3}{*}{ rs7908 } & \multirow{3}{*}{$\mathrm{BbvC1}$} & $5^{\prime}-\mathrm{CC}^{\wedge} \mathrm{TCAGC}-3^{\prime}$ & & & GG: $225 \mathrm{bp}$ \\
\hline & & & $37^{\circ} \mathrm{C}$ & 16 hours & GC: $225,183,42 \mathrm{bp}$ \\
\hline & & $3^{\prime}-\mathrm{GGAGT}^{\wedge} \mathrm{CG}-5^{\prime}$ & & & CC: $183,42 \mathrm{bp}$ \\
\hline \multirow{3}{*}{ rs10180391 } & \multirow{3}{*}{ Ase1 } & $5^{\prime}-\mathrm{AT}^{\wedge} \mathrm{TAAT}^{\prime} 3^{\prime}$ & & & CC: 209 bp \\
\hline & & & $37^{\circ} \mathrm{C}$ & 16 hours & CT: 209, 145, 64 bp \\
\hline & & $3^{\prime}-\mathrm{TAAT}^{\wedge} \mathrm{TA}-5^{\prime}$ & & & TT: $145,64 \mathrm{bp}$ \\
\hline
\end{tabular}
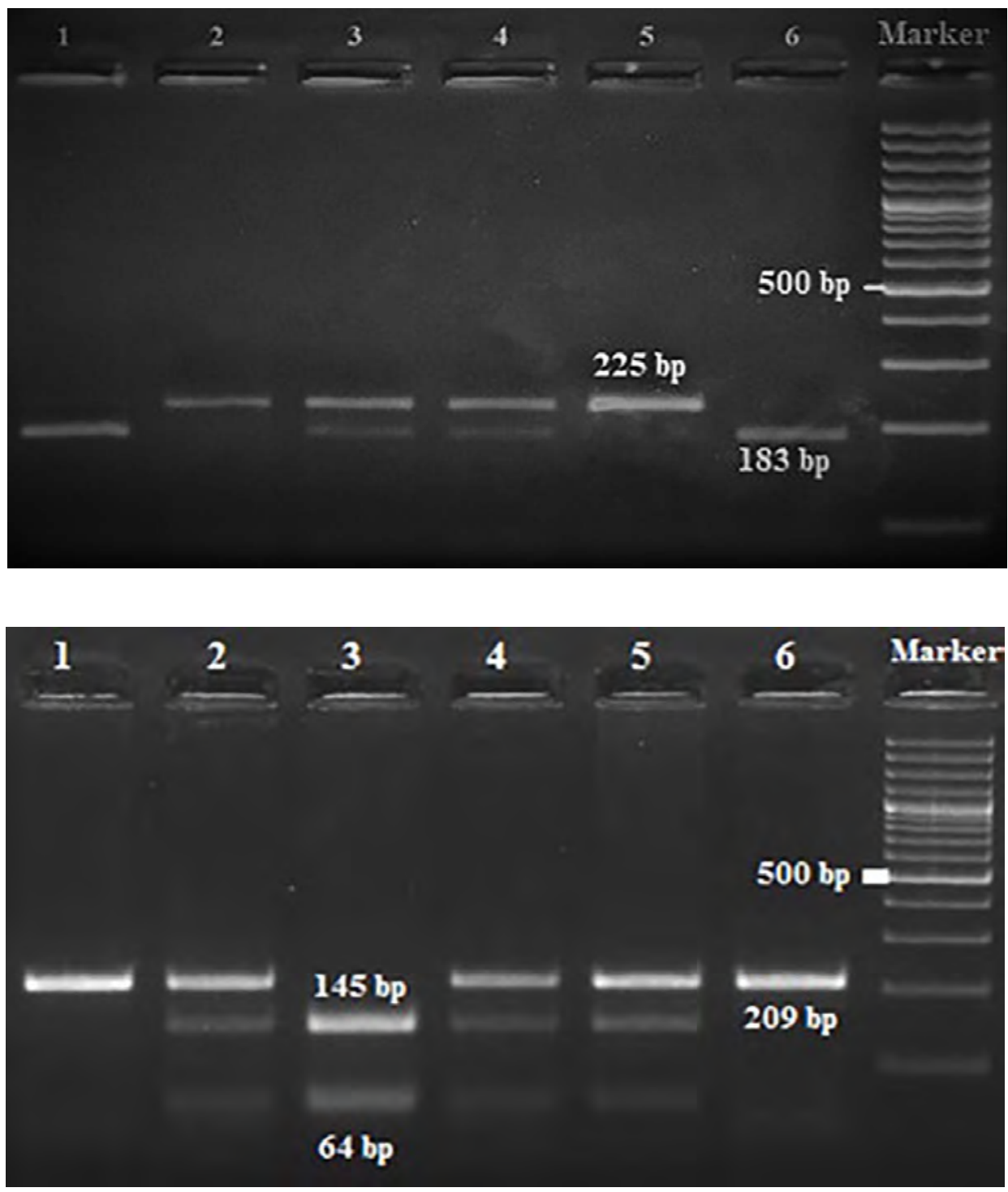

FiguRE 1: GNLY rs7908 gene polymorphism gel electrophoresis image. DNA marker is $100 \mathrm{bp}$. Samples with 3,4 are GC; samples with 1, 6 are CC and 2,5 with GG genotype
FIGURE 2: GNLY rs10180391 gene polymorphism gel electrophoresis image. DNA marker is100 bp. Samples 2,4,5 CT; samples 1 and 6 are in CC and 3 are in TT genotype 
groups ( $p>0.05$ ). No statistically significant difference was found between patients and controls for GNLY rs10180391 allele frequencies $(p=0.604, O R=1.114, C I=0.741-1.627)$. Neither was there any statistically significant difference in GNLY rs7908 (C/G) and GNLY rs10180391 (C/T) gene polymorphisms in terms of psoriasis severity (PASI) (Graph 1). In addition, there was no statistically significant association between GNLY rs7908 (C/G) and rs10180391 (C/T) gene polymorphisms in terms of haplotype (Table 5).

\begin{tabular}{llll}
\multicolumn{5}{r}{ TABLE 3: Sex and age distribution of psoriasis patients and } \\
controls
\end{tabular}

\section{DISCUSSION}

Psoriasis is a dermatosis characterized by sharply demarcated erythematous, pearly-white scales whose etiology is not clearly

\begin{tabular}{|c|c|c|c|c|}
\hline $\begin{array}{l}\text { Haplotype } \\
\text { rs7908/ } \\
\text { rs10180391 }\end{array}$ & $\begin{array}{l}\text { Healthy } \\
\text { controls } \\
{[n=100(\%)]}\end{array}$ & $\begin{array}{l}\text { Psoriasis } \\
\text { patients } \\
{[n=100(\%)]}\end{array}$ & $\begin{array}{c}P \\
\text { value }\end{array}$ & $\begin{array}{c}\text { OR } \\
(95 \% \mathrm{CI})\end{array}$ \\
\hline GC & $39 \%$ & $42.5 \%$ & 0.036 & Reference \\
\hline GT & $20 \%$ & $29 \%$ & 0.269 & $\begin{array}{c}1.331 \\
(0.802-2.208)\end{array}$ \\
\hline $\mathrm{CC}$ & $25.5 \%$ & $19.5 \%$ & 0.180 & $\begin{array}{c}0.702 \\
(0.418-1.178)\end{array}$ \\
\hline CT & $15.5 \%$ & $9 \%$ & 0.060 & $\begin{array}{c}0.533 \\
(0.276-1.028)\end{array}$ \\
\hline
\end{tabular}

\section{TABLE 4: GNLY genotypes and alleles and the risk of developing psoriasis}

\begin{tabular}{|c|c|c|c|c|c|c|c|}
\hline & $(n=100)$ & All & PASI $<3$ & $3 \leq \mathrm{PASI}<1$ & PASI $\geq 10$ & \multirow{2}{*}{$\begin{array}{l}\text { OR }(95 \% \mathrm{CI}) \\
\text { for all psoriasis }\end{array}$} & \multirow{2}{*}{$\begin{array}{c}P \\
\text { value }\end{array}$} \\
\hline & n $(\%)$ & n $(\%)$ & n $(\%)$ & n $(\%)$ & n $(\%)$ & & \\
\hline \multicolumn{8}{|c|}{ Rs7908/Genotype } \\
\hline GG & $37(37 \%)$ & $51(51 \%)$ & $28(46.7 \%)$ & $17(53.1 \%)$ & $6(75 \%)$ & Reference & \multirow{3}{*}{0.033} \\
\hline GC & $44(44 \%)$ & $41(41 \%)$ & $25(41.7 \%)$ & $14(43.8 \%)$ & $2(25 \%)$ & $0.676(0.371-1.232)$ & \\
\hline $\mathrm{CC}$ & $19(19 \%)$ & $8(8 \%)$ & $7(11.7 \%)$ & $1(3.1 \%)$ & $0(0.0 \%)$ & $0.305(0.121-0.773)$ & \\
\hline \multicolumn{8}{|c|}{ Rs7908/Allele } \\
\hline G & $118(59 \%)$ & $143(71.5 \%)$ & $81(67.5 \%)$ & $48(75 \%)$ & $14(87.5 \%)$ & Reference & \multirow{2}{*}{0.009} \\
\hline $\mathrm{C}$ & $82(41 \%)$ & $57(28.5 \%)$ & $39(32.5 \%)$ & $16(25 \%)$ & $2(12.5 \%)$ & $0.574(0.378-0.870)$ & \\
\hline \multicolumn{8}{|c|}{ rs10180391/Genotype } \\
\hline $\mathrm{CC}$ & $44(44 \%)$ & $41(41 \%)$ & $28(46.7 \%)$ & $11(34.4 \%)$ & $2(25 \%)$ & Reference & \multirow{3}{*}{0.886} \\
\hline $\mathrm{CT}$ & $41(41 \%)$ & $42(42 \%)$ & $22(36.7 \%)$ & $15(46.9 \%)$ & $5(62.5 \%)$ & $1.099(0.600-2.013)$ & \\
\hline TT & $15(15 \%)$ & $17(17 \%)$ & $10(16.7 \%)$ & $6(18.8 \%)$ & $1(12.5 \%)$ & $1.216(0.539-2.746)$ & \\
\hline \multicolumn{8}{|c|}{ rs10180391/Allele } \\
\hline $\mathrm{C}$ & $129(64.5 \%)$ & $124(62 \%)$ & $78(65 \%)$ & $37(57.8 \%)$ & $9(56.3 \%)$ & Reference & \multirow{2}{*}{0.604} \\
\hline $\mathrm{T}$ & $71(35.5 \%)$ & $76(38 \%)$ & $42(35 \%)$ & $27(42.2 \%)$ & $7(43.7 \%)$ & $1.114(0.741-1.672)$ & \\
\hline
\end{tabular}

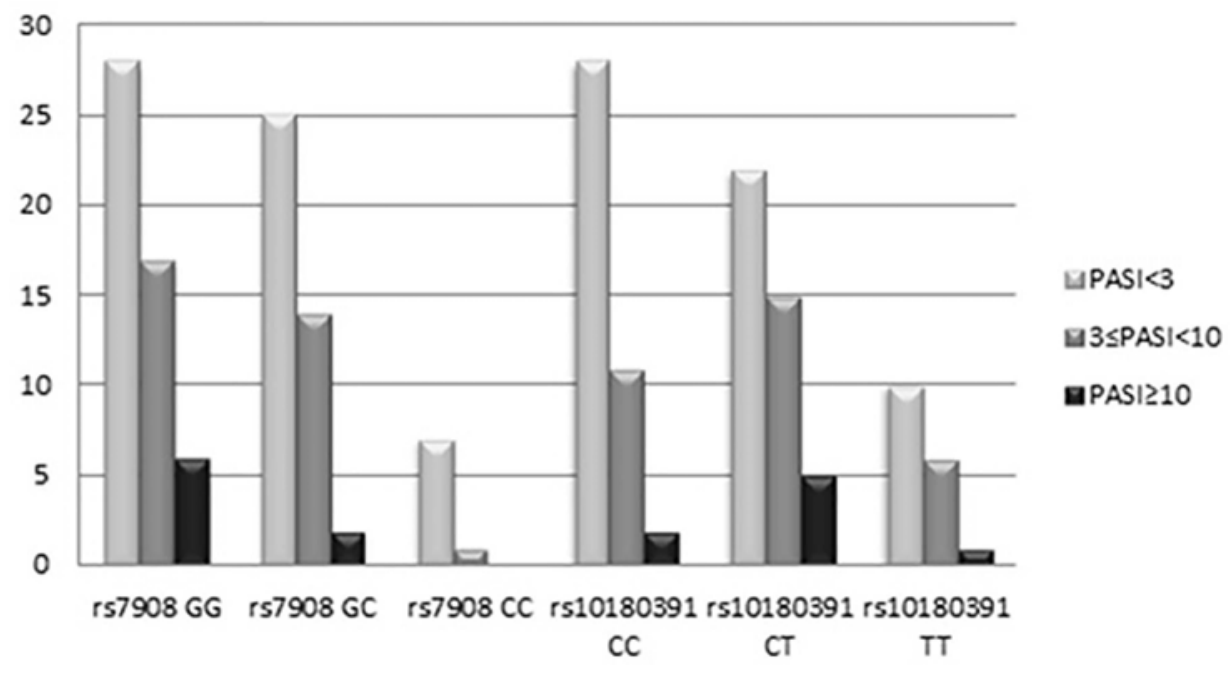

Graph 1: The relationship between PASI score and GNLY genotypes 
known. ${ }^{5}$ According to current knowledge, genetic factors contribute to age at onset, clinical manifestations, and type and severity of the disease. It has been hypothesized that genetic differences may lead to the development of the disease (PSORS2) and/or affect the initial antigen presentation (PSORS1 associated with the HLA-Cw6 locus). ${ }^{13,14}$ The most widely accepted mechanism in the etiopathogenesis of psoriasis involves chemokines, which play a key role in cytokine and lymphocyte activation as the fundamental step in this process, followed by keratinocyte hyperproliferation and inflammation. ${ }^{15,16}$

Granulysin, a positively charged cytolytic antimicrobial peptide (AMP) class found in the granules of cytotoxic T lymphocytes (CTL) and natural killer cells (NK), was first described during the investigation of genes expressed in effector T lymphocytes. ${ }^{17}$ Granulysin has been associated with a number of diseases, including various infections, cancer, transplantation, skin disorders, and reproductive complications. ${ }^{18}$

We investigated the relationship between psoriasis, an autoinflammatory disease, and rs7908 (G/C) and rs10180391 (C/T) gene polymorphisms in the GNLY gene. We found no study in the literature on the relationship between psoriasis and GNLY gene polymorphisms. The role of GNLY gene polymorphisms has been investigated in chronic liver disease and HIV infection. ${ }^{12,19}$

The difference between the two groups in the genotype distribution of GNLY rs7908 (C/G) polymorphism was statistically significant. CC genotype was significantly more frequent than GG genotype in the control group. In terms of allelic frequencies, the $\mathrm{C}$ allele has been found to have a protective effect against psoriasis. Due to the alternative splicing mechanism from the GNLY gene, four different protein variants are synthesized in the same cell. In GNLY rs7908 (C/G) variants 1, 2, and 3, this polymorphism occurs in the $3^{\prime}$ UTR region. ${ }^{20}$ Stabilization of the mRNA, exocytosis, and subcellular localization are affected by $3^{\prime}$ UTR. Therefore, the gene expression is post-transcriptionally regulated. ${ }^{21}$ Nucleotide changes in the $3^{\prime} \mathrm{UTR}$ region lead to serious disruption..$^{22}$ In the variant GNLY rs 7908, C/G nucleotide exchange is located in the protein-coding region, causing the amino acid transformation of leucine $\rightarrow$ valine (Leu150Val). Therefore, it is thought that GNLY rs7908 C allele reduces the amount or activity of granulysin protein, leading to the complete elimination of trigger factors causing psoriasis. The amino acid change imposed by the rs7908 SNP can be considered as a reason of activity decrease of the enzyme. Although both leucine and valine are nonpolar and hydrophobic, valine differs structurally from leucine, containing an extra methylene $\left(-\mathrm{CH}_{2}\right)$ group. Most likely, the absence of the methyl group causes distortions in intramolecular interactions and decreases in enzyme activity.

When the GNLY rs10180391 gene polymorphism genotype distribution and allele frequencies were analyzed, no statistically significant difference was found between the patient and control groups. In contrast, Hou et al. (2015) found a statistically significant association between GNLY rs1866139 and GNLY rs11127 and HBV infection. ${ }^{12}$ This may be due to the fact that the GNLY rs1866139 and GNLY rs11127 polymorphisms are not effective in protein activity or amount. When the patient group was classified as PASI $<3,3 \leq$ PASI $<10$, PASI $\geq 10$ according to the PASI severity score, there was no statistically significant change in terms of the two polymorphisms. However, CC ratio was decreased in GNLY rs7908 polymorphism as the PASI score increased with GG and GC. In other words, CC genotype frequency decreased as disease severity increased. This decrease was not statistically significant because of the low number of cases. The study showed that GNLY rs7908 G allele is associated with disease severity and that the $C$ allele protects against psoriasis. The increase in psoriasis severity associated with the GNLY rs7908 $G$ allele in our study suggests that this allele may have an enhancing effect on granulase expression. Similarly, Elgarhy et al. (2015) found that the severity of psoriasis increased with the increase in granulysin expression. They corroborated our findings, and their immunohistochemical analyses showed that granulysin expression is increased in psoriasis lesions. ${ }^{7}$ Raychaudhuri et al. (2004) found increased granulysin levels in lesional $\mathrm{T}$ cells and dermal dendrocytes in psoriasis plaques. ${ }^{23}$ Pivarcsi et al. (2004) showed that lichen planus (LP) granulysin was expressed 100-200 times above the normal level. ${ }^{24}$ Granulysin has been identified as an important effector in both Stevens-Johnson syndrome (SJS) and diffuse keratinocyte death in toxic epidermal necrolysis (TEN). ${ }^{25}$ Tewary et al. (2010) demonstrated that granulysin promotes CTL proliferation by acting as an alarmin with chemoattractant and stimulatory effects on dendritic cells and macrophages. ${ }^{26}$ Our study suggests that the rs7908 $\mathrm{C} / \mathrm{G}$ polymorphism in the GNLY gene may also reduce the alarmin function of granulysin, thus allowing the cells of the immunopathogenesis of psoriasis to continue to function normally.

Our study analyzed GNLY rs7908 and GNLY rs10180391 SNPs and found that the C allele of rs7908 is protective against psoriasis and even inversely proportional to psoriasis severity. There are very few studies in the literature that examine the interactions between GNLY gene polymorphisms and immunological diseases. There is thus serious need for further research to identify the effect of granulysin in psoriasis. Psoriasis prevalence is reported at 1.5-2.8\% in the United Kingdom, 2.5-3.5\% in Germany, 3.15\% in the United States, and $0.05-1.23 \%$ in China, and the highest prevalence in Asia was reported at $11.8 \%{ }^{27}$ Since prevalence of the disease differs between populations, our research in the Turkish population can be useful for elucidating the role of GNLY in psoriasis.

\section{CONCLUSION}

We found that genotype GNLY rs7908 CC and C allele had a protective effect against psoriasis and reduced the severity of the disease. The rs10180391 SNP did not play a significant role in the pathogenesis of psoriasis. Investigation of the effect of GNLY rs7908 and GNLY rs10180391 gene polymorphisms on psoriasis risk and disease progression can lead to the development of new treatment modalities for psoriasis.

Acknowledgments: The research was supported by the Unit of Scientific Research Projects of Bulent Ecevit University (BAP2015-50737594-04), Turkey. 口 


\section{REFERENCES}

1. Capon F. The Genetic Basis of Psoriasis. Int J Mol Sci. 2017;18. pii: E2526

2. Łakuta P, Marcinkiewicz K, Bergler-Czop B, Brzezińska-Wcisło L, Słomian A. Associations between site of skin lesions and depression, social anxiety, bodyrelated emotions and feelings of stigmatization in psoriasis patients. Postepy Dermatol Alergol. 2018; 35:1-60. Postepy Dermatol Alergol. 2018;35:60-6

3. Griffiths CEM, Camp RDR, Barker JNWN. Psoriasis. In: Burns T, Breathnach S, Cox $\mathrm{N}$, Griffiths C, editors. Rook's textbook of dermatology. Oxford: Blackwell Science, 2004. p. 35-1.

4. Nazik H, Nazik S, Gul FC. Body image, self-esteem, and quality of life in patients with psoriasis. Indian Dermatol Online J. 2017;8:343-6.

5. Levi SS, Ramot Y. Gender differences in psoriasis. In: Tur E, Maibach HI, editors. Gender and dermatology. Cham: Springer; 2002. p. 63-81.

6. Davidovici BB, Sattar N, Prinz J, Puig L, Emery P, Barker JN, et al. Psoriasis and systemic inflammatory diseases: potential mechanistic links between skin disease and co-morbid conditions. J Invest Dermatol. 2010;130:1785-96.

7. Elgarhy LH, Shareef MM, Moustafa SM. Granulysin expression increases with increasing clinical severity of psoriasis. Clin Exp Dermatol. 2015;40:361-6.

8. Wang G. Human antimicrobial peptides and proteins. Pharmaceuticals (Basel). 2014:7:545-94

9. Marcinkiewicz M, Majewski S. The role of antimicrobial peptides in chronic inflammatory skin diseases. Postepy Dermatol Alergol. 2016;33:6-12.

10. Krensky AM, Clayberger C.. Biology and clinical relevance of granulysin. Tissue Antigens. 2009;73:193-8.

11. ncbi.nlm.nih.gov [Internet]. National Center for Biotechnology Information Search [Cited 2017 Dec 11]. Available from: https://www.ncbi.nlm.nih.gov/ snp/?term $=$ GNLY

12. Hou SH, Hu J, Zhang Y, Li QL, Guo JJ. Effects of interaction between genetic variants in human leukocyte antigen $\mathrm{DQ}$ and granulysin genes in Chinese Han subjects infected with hepatitis B virus. Microbiol Immunol. 2015;59:209-18.

13. Kim J, Krueger JG. The immunopathogenesis of psoriasis. Dermatol Clin. 2015;33:13-23.
14. Puig L, Julià A, Marsal S. The pathogenesis and genetics of psoriasis. Actas Dermosifiliogr. 2014;105:535-45.

15. Lowes MA, Suárez-Fariñas M, Krueger JG. Immunology of psoriasis. Annu Rev Immunol. 2014;32:227-55

16. Mahil SK, Capon F, Barker JN. Update on psoriasis immunopathogenesis and targeted immunotherapy. Semin Immunopathol. 2016;38:11-27.

17. Wei HM, Lin LC, Wang CF, Lee YJ, Chen YT, Liao YD. Antimicrobial properties of an immunomodulator-15 kDa human granulysin. PLoS One. 2016;11:e0156321.

18. Krensky AM, Clayberger C. Biology and clinical relevance of granulysin. Tissue Antigens. 2009;73:193-8.

19. Park GH, Kim KY, Cheong JY, Cho SW, Kwack K. Association of GNLY genetic polymorphisms with chronic liver disease in a Korean population. DNA Cell Biol. 2012;31:1492-8.

20. Ensembl.org [Internet]. Ensembl Genome Browser 90 [updated 2017 Dec; cited 2017 Dec 11]. Available from: https://www.ensembl.org/index.htm

21. Di Liegro CM, Schiera G, Di Liegro I. Regulation of mRNA transport, localization and translation in the nervous system of mammals. Int J Mol Med. 2014;33:747-62.

22. Schwerk J, Savan R. Translating the untranslated region. J Immunol. 2015;195:2963-71.

23. Raychaudhuri SP, Jiang WY, Raychaudhuri SK, Krensky AM. Lesional T cells and dermal dendrocytes in psoriasis plaque express increased levels of granulysin. $J$ Am Acad Dermatol. 2004;51:1006-8.

24. Pivarcsi A, Kemény L, Dobozy A. Innate immune functions of the keratinocytes. Acta Microbiol Immunol Hung. 2004;51:303-10.

25. Mawson AR, Eriator I, Karre S. Stevens-Johnson syndrome and toxic epiderma necrolysis (SJS/TEN): could retinoids play a causative role? Med Sci Monit. 2015;21:133-43.

26. Tewary P, Yang D, de la Rosa G, Li Y, Finn MW, Krensky AM, et al. Granulysin activates antigen-presenting cells through TLR4 and acts as an immune alarmin. Blood. 2010;116:3465-74.

27. Chandran V, Raychaudhuri SP. Geoepidemiology and environmental factors of psoriasis and psoriatic arthritis. J Autoimmun. 2010;34:J314-21.

Conception and planning of the study; Obtaining, analyzing, and interpreting the data; Elaboration and writing of the manuscript; Effective participation in research orientation; Critical review of the literature

Sevim Karakas Celik $\quad$ (iD) ORCID 0000-0003-0505-7850

Statistical analysis; Approval of the final version of the manuscript; Conception and planning of the study; Critical review of the literature; Critical review of the manuscript

Nilgun Solak

(iD) ORCID 0000-0002-6572-9615

Conception and planning of the study

Gunes Cakmak Genc $\quad$ (iD) ORCID 0000-0001-7222-0377

Conception and planning of the study; Obtaining, analyzing, and interpreting the data

Ahmet Dursun $\quad$ (iD) ORCID 0000-0002-7625-837X

Approval of the final version of the manuscript; Critical review of the literature

How to cite this article: Ermis E, Karakas Celik S, Solak N, Cakmak Genc G, Dursun A. The role of GNLY gene polymorphisms in psoriasis pathogenesis. An Bras Dermatol. 2019;94(2):198-203 